\title{
POTENCIALIDADES E DIFICULDADES DE ESTUDANTES DE ENGENHARIA NA DISCIPLINA DE CÁLCULO I EM TEMPOS DE PANDEMIA
}

DOI: 10.37702/2175-957X.COBENGE.2021.3510

Márcia Jussara Hepp Rehfeldt - mrehfeld@univates.br

Universidade do Vale do Taquari UNIVATES

Salgado Filho 169

95890-000 - Teutônia - RS

Marli Teresinha Quartieri - mtquartieri@univates.br

Centro Universitário Univates

Rua Sergipe 84

95900-000 - Lajeado - RS

leda Maria Giongo - igiongo@univates.br

Univates

Marechal Floriano, 1900

95735-000 - Roca Sales - RS

Sônia Elisa Marchi Gonzatti - soniag@univates.br

UNIVATES

Rua Arnaldo Becker Altmeyer 431

95913-028 - Lajeado - RS

Resumo: Este artigo traz uma investigação realizada com 34 estudantes matriculados na disciplina de Cálculo I, no semestre B de 2020. O objetivo foi analisar dificuldades, potencialidades e sugestões destacadas pelos estudantes em relação ao Ensino Remoto Emergencial (ERE) na disciplina de Cálculo I. Para obter estas informações foi disponibilizado, inicialmente, um questionário contendo perguntas abertas sobre aulas virtualizadas na disciplina de Cálculo I. Ao final do semestre, uma questão, mais ampla, foi novamente encaminhada contemplando aspectos similares. As respostas de ambos os instrumentos foram analisadas imbricando-os com referenciais teóricos. Como resultados, os estudantes citam a organização tempo/espaço e a falta de base matemática como aspectos que dificultam a aprendizagem de alguns conteúdos. Como potencialidades destacam 
a não necessidade de deslocamento até a instituição, o uso do quadro, exercícios detalhados, gravações das explicações pelo google meet. No final do semestre todos destacaram que ocorreu entendimento em relação aos conteúdos de Cálculo I, entretanto para isso ocorrer houve necessidade do professor usar diferentes meios, em especial aqueles que fomentam a interação do estudante. $E$, o estudante precisa manter o foco, concentração e participar ativamente das atividades propostas.

Palavras-chave: Aulas virtualizadas. Cálculo I. Dificuldades e potencialidades. 


\section{POTENCIALIDADES E DIFICULDADES DE ESTUDANTES DE ENGENHARIA NA DISCIPLINA DE CÁLCULO I EM TEMPOS DE PANDEMIA}

\section{INTRODUÇÃO}

Planejar e desenvolver aulas em tempos de pandemia tem sido uma tarefa árdua para atores que estão em cena no ensino de Ciências Básicas, em cursos vinculados às engenharias. De acordo com Bezerra (2020), recai sobre os gestores a necessidade de reinventarem novas formas de prover o ensino, mantendo a qualidade. No entanto, o professor é quem está na linha de frente, sendo desafiado a gravar e postar vídeos, usar softwares, explorar plataformas de interação e se tornar um bom comunicador; enfim, dominar, com razoável habilidade, as Tecnologias da Comunicação e Informação (MENDES et al., 2021; SANTOS et al., 2020; DUTRA; SILVA et al., 2020).

Além desses aspectos de formação técnica, alguns professores, no decorrer de 2020, buscaram melhorar suas conexões e, para isso, compraram e passaram a usar mesas digitalizadoras e, por vezes, quadros brancos presos às paredes de suas casas, tudo em prol de uma aula com qualidade. Esta, por exemplo, foi uma realidade que ocorreu na Instituição de Ensino Superior em que as autoras deste artigo atuam. Em adição, houve ocasiões em que os docentes se depararam com questionamentos sobre o processo de ensino, bem como a aprendizagem dos estudantes. Estariam eles, de fato, aprendendo? $\mathrm{O}$ que pensam sobre as aulas virtualizadas, uma vez que não escolheram essa modalidade de ensino; ao contrário, contrataram aulas presenciais?

Em efeito, este artigo tem como objetivo analisar dificuldades, potencialidades e sugestões apontadas pelos alunos em relação ao Ensino Remoto Emergencial (ERE), na disciplina de Cálculo I. Estudantes de uma universidade comunitária, eles pagam mensalidades e têm, em sua maioria, acesso às tecnologias, seja por meio de smartphones ou notebooks, em geral, com boa conexão à internet. Para obter informações acerca da percepção das aulas, os trinta e quatro matriculados no segundo semestre de 2020 , na disciplina de Cálculo I, responderam, no início do semestre, perguntas cujo cerne pairava sobre as potencialidades e dificuldades do Ensino Remoto Emergencial. Ao final do semestre, novamente foram indagados, por meio de uma pergunta inserida em uma avaliação, expressando-se acerca das percepções que tiveram sobre as aulas virtualizadas na referida disciplina.

Cabe salientar que, na Instituição de Ensino Superior em que foi desenvolvido o estudo, houve apenas um dia de "parada" das aulas, em março de 2020 , sendo que, no segundo dia de fechamento da universidade, os professores já estavam atuando em modo remoto com aulas virtualizadas. Para especificar, faz-se uso de materiais postados em um ambiente virtual, no caso o Moodle, no qual é possível inserir links de vídeos (em geral, gravados pelos professores), arquivos com materiais de aula, links para videoconferências, fóruns, entre outros recursos. Em adição, os docentes permanecem à disposição todo o horário de aula, ou seja, das dezenove às vinte e duas horas e trinta minutos, como se fossem aulas presenciais, o mesmo ocorrendo com os estudantes. A metodologia também é similar às presenciais, pois os professores explicam conteúdos, passam exercícios, promovem trabalhos em grupos, tudo de forma virtualizada. Para tal, utilizam mesas digitalizadoras, quadro branco, slides, textos, entre outros recursos.

Vale mencionar que, na disciplina Cálculo I, estavam matriculados estudantes de distintas Engenharias, tais como Engenharia Civil, Engenharia Química, Engenharia 
Elétrica, Engenharia da Produção, Engenharia Mecânica, Engenharia de Software. Para cursar a referida disciplina, todos os estudantes frequentam, como pré-requisito, a disciplina de Introdução às Ciências Exatas. Em Cálculo I, os conteúdos estão relacionados com derivadas e integrais.

Como metodologia de ensino, no segundo semestre de 2020, desenvolveram-se aulas expositivas e dialogadas. Estas contaram com apoio de ferramentas tecnológicas; elaboração de vídeos, cujas atividades envolviam os conteúdos desenvolvidos na disciplina; troca de experiências, a partir da exposição oral e escrita dos estudantes, com resolução de listas de exercícios e situações-problema, resolvidas individualmente ou em pequenos grupos; pesquisas práticas, voltadas à interpretação do cálculo presente em atividades do cotidiano de um futuro profissional.

\section{REFERENCIAL TEÓRICO}

As aulas que ocorreram ao longo de 2020 e ainda estão em andamento, receberam algumas denominações distintas, tais como "Ensino Remoto Emergencial" (DUTRA; SILVA et al., 2020; BEHAR, 2020; FERREIRA et al., 2020; MENDES et al., 2021; SANTOS et al., 2020), Ensino a Distância ou ainda Aulas Virtualizadas. Há autores que entendem que ela [a denominação ensino remoto emergencial] mantém uma relação ou proximidade com as aulas na modalidade EAD, da mesma forma como as Aulas Virtualizadas com a EaD. No entanto, de acordo com Behar (2020, texto digital), o ERM é distinto da Educação a Distância, pois

O termo "remoto" significa distante no espaço e se refere a um distanciamento geográfico. O ensino é considerado remoto porque os professores e alunos estão impedidos por decreto de frequentarem instituições educacionais para evitar a disseminação do vírus. É emergencial porque do dia para noite o planejamento pedagógico para o ano letivo de 2020 teve que ser engavetado.

Em outras palavras, houve a necessidade de adaptar as aulas e as replanejar às pressas, por isso o nome emergencial. Ainda, para Behar (2020, texto digital), "Foi preciso pensar em atividades pedagógicas mediadas pelo uso da internet, pontuais e aplicadas em função das restrições impostas pela covid-19 para minimizar os impactos na aprendizagem advindos do ensino presencial".

De acordo com o site https://www.ead.com.br/aula-virtual, "aulas virtuais fazem parte do chamado Ensino a Distância". Além do mais, "Na prática, uma aula virtual pode ser ministrada basicamente de duas maneiras. A primeira é a videoaula, gravada pelo professor ou tutor do curso. A segunda ocorre em tempo real e é chamada de videoconferência" (www.ead.com.br/aula-virtual), modelo que foi adotado pela Universidade em que as autoras deste texto atuam como professoras de Ciências Básicas, em cursos de Engenharia, usando proeminentemente as videoconferências, que

[...] são aulas transmitidas ao vivo ao estudante, em horário previamente agendado. Podem ter um caráter mais personalizado ou mais integrado à turma de alunos. Muitas vezes, por exemplo, essas aulas são emitidas via satélite a partir de uma unidade da faculdade onde está ocorrendo uma aula presencial. O aluno, então, pode assistir a todo o evento e ainda participar enviando perguntas e comentários. Esse tipo de tecnologia possibilita que alunos e professores estabeleçam uma comunicação bidirecional em tempo real (https://www.ead.com.br/aula-virtual). 
Ainda sobre o Ensino Remoto Emergencial, Mendes et al. (2020, p. 1) afirmam que "nesse tipo de ensino novos desafios surgem, novas ferramentas de tecnologia são utilizadas, novas formas de avaliação, e isso tudo requer uma nova adaptação, com novos aprendizados". Para Behar (2020, texto digital), "o professor de uma hora para outra teve que trocar o 'botão' para mudar de sintonia e começar a ensinar e aprender de outras formas".

Outro fator relativo ao ERE que merece ser ressaltado é a mudança do papel do professor. Alguns autores (DUTRA; SILVA et al., 2020, SANTOS et al., 2020) mencionam que ele pode favorecer o protagonismo dos estudantes no processo de aprendizagem, pois ele deixa de ser o centro no processo de ensino. Assim, esse modelo favorece o uso de metodologias ativas, colocando o aluno como sujeito dos processos de ensino e de aprendizagem, também preconizado por Demo (2011).

Como pode ser visto, o ERE apresenta potencialidades e dificuldades. Em relação àquelas, podem-se incluir

[...] a flexibilidade, menos gastos com transporte, alimentação e até mesmo materiais, que passam a ser fornecidos de forma virtual e gratuita muitas das vezes. No entanto, é necessário corrigir as desvantagens presentes, para que se iguale cada vez mais ao ensino presencial (Mendes et al., 2020, p. 5)

No que tange às dificuldades, Mendes et al. (2020) relatam os desafios tecnológicos que estudantes e professores enfrentam. Na Instituição em que este trabalho foi realizado, esse fato não foi percebido fortemente, pois vários professores já haviam participado de uma formação continuada para aulas no formato EaD, sendo algumas conteudistas (responsáveis pela escrita do material para cálculo na modalidade EaD). Em adição, os alunos também já estavam habituados com Ambientes Virtuais de Aprendizagem, visto que estes são usados como apoio ao ensino presencial.

Outro aspecto levantado por Dutra e Silva et al. (2020) é a sensação de isolamento, pois, nas aulas remotas, as plataformas de comunicação permitem ao estudante fechar a sua imagem. Particularmente, entende-se ser essa uma dificuldade, pois a interação entre professor e aluno necessita de um olhar para o outro, perceber se o discente concorda ou pelos movimentos produzidos pela sua cabeça, por exemplo. Nessa mesma linha, Biottto e Serra (2020, p. 1) realizaram uma investigação com alunos do Curso de Engenharia Civil e constataram que estes "não conseguiram superar o impacto psicológico que a pandemia teve sobre a sua saúde mental e motivá-los ao estudo num ambiente de distanciamento social".

\section{METODOLOGIA}

Este estudo apresenta características de uma pesquisa com abordagem qualitativa e, quanto aos procedimentos, entende-se ser uma aproximação de estudo de caso. Para Sampieri, Collado e Lucio (2013, p. 33),

A pesquisa qualitativa se fundamenta em uma perspectiva interpretativa centrada no entendimento do significado das ações de seres vivos, principalmente dos humanos e suas instituições (busca interpretar aquilo que vai captando ativamente).

Nesta pesquisa, em particular, pretendeu-se interpretar e analisar o que os estudantes apontavam como potencialidades, dificuldades e sugestões em relação às aulas virtualizadas, na disciplina de Cálculo I, em que se usa plataforma google meet para 
comunicação (videoconferências). Cabe lembrar que, durante essas aulas, os professores permanecem todo o tempo online, e os alunos podem questionar e perguntar a qualquer momento no decorrer da aula.

Para obter os dados para este estudo, a professora de Cálculo I, na primeira aula da disciplina, no segundo semestre de 2020, postou, no Ambiente Virtual, um questionário, contendo cinco perguntas. Estas foram respondidas no decorrer da aula, e as respostas postadas no mesmo local. Especificamente, este trabalho socializou a análise de três das cinco questões, além de uma que foi aplicada no último dia de aula para receber feedback em relação às aulas virtualizadas.

Quanto ao questionário inicial, estas foram as três questões:

a. Neste período de pandemia, quais são suas maiores dificuldades em relação às aulas virtualizadas?

b. O que você considera produtivo nas aulas virtualizadas?

c. Que sugestões você daria para as nossas aulas virtualizadas de Cálculo I?

A última pergunta, feita na prova final da disciplina, mas sem valor avaliativo, foi: Escrever de quatro a dez linhas, destacando dificuldades e aprendizagens ocorridas no decorrer deste semestre na disciplina de Cálculo I. Destaca-se que, embora não sendo avaliada, ela foi respondida pelos trinta e quatro estudantes presentes à aula.

As respostas foram digitalizadas e lidas para análise. Nas questões a) e c), elas foram agrupadas de acordo com a semelhança; na letra b), em função da diversidade, a junção não ocorreu. Já na questão final, após análise detalhada de todas as respostas, selecionaram-se algumas para serem discutidas neste trabalho, sendo as mais representativas dentre as coletadas. Na próxima seção, apresenta-se a análise efetivada, imbricando-se os dados com o referencial teórico discutido anteriormente.

\section{RESULTADOS OBTIDOS}

Nesta seção, são discutidos os dados coletados em cada uma das questões apresentadas na metodologia. Todos os trinta e quatro estudantes da disciplina de Cálculo I que responderam às questões propostas tiveram experiência com alguma disciplina na forma virtualizada no decorrer do primeiro semestre de 2020, pois a Instituição parou suas atividades letivas apenas um dia (conforme já comentado anteriormente).

Para a análise da questão "Neste período de pandemia, quais são suas maiores dificuldades em relação às aulas virtualizadas?", as respostas foram organizadas em quatro grupos: dificuldades relacionadas à problemas de conexão à internet (quatro estudantes); dificuldades em relação aos conteúdos (quinze); organização do tempo/espaço (dez). Além disso, cinco citaram que não possuíam dificuldades quanto às aulas virtualizadas.

No grupo "dificuldades em relação aos conteúdos", destacam-se, nas respostas, a falta de conhecimentos de alguns conceitos básicos relacionados à matemática e a demora em entender o conteúdo. As respostas selecionadas reiteram a afirmação:

Minha única dificuldade se não tiver exercícios para reforçar o conteúdo eu não aprendo rápido (E2).

Falta de base, pois faz muitos anos que me formei no ensino médio. Mas estou me virando bem. Já revisei boa parte do conteúdo e estou sempre ligado a canais de youtubers de professores de matemática e física (E5).

Por não estar estudando o conteúdo de forma presencial, acaba parecendo que se esquece mais fácil o conteúdo (E8).

Ter a visualização de como se fazer os princípios básicos do conteúdo (E20).

Muitas vezes, a questão de tirar dúvidas e um pouco a velocidade como é dada a aula pelo professor. Como estamos com aulas virtualizadas, acredito 
que quando o professor irá explicar o conteúdo (que para mim é a parte que eu mais devo prestar atenção), ele deve explicar de uma forma mais devagar. É difícil, às vezes, pegar todos os tópicos de Cálculo com uma explicação muito rápida, ainda mais quando não se tem uma base muito boa do ensino médio [...]. Às vezes, sinto muita dificuldade nessa área e isso tem me prejudicado muito (E24).

De acordo com os excertos anteriores, pode-se inferir que os estudantes precisavam de explicações detalhadas dos conteúdos, o que também ocorria na modalidade presencial. O fato é que eles consideravam as disciplinas relacionadas ao Cálculo as mais difíceis em função da formalidade e abstração. Entretanto, no ensino virtualizado, esta dificuldade parece ter se acentuado, pois, de repente, a forma do ensino, que era presencial, passou a ser por meio do google meet, e os alunos e professores não estavam preparados para essa mudança rápida.

Nesse sentido, E5 destaca que "Já revisei boa parte do conteúdo e estou sempre ligado a canais de youtubers de professores de matemática e física". Esse comentário corrobora o pensamento de Justino (2020, texto digital), que salienta que os estudantes estão percebendo que podem aprender fora da sala de aula, e a internet tem diversas lições que auxiliam no entendimento dos conteúdos. De fato, nela há muita informação, mas cabe ao docente, no decorrer das aulas virtualizadas, debater com os alunos o quanto é importante fazer "uma filtragem" das informações, bem como comentar sobre sites confiáveis.

No grupo "organização do tempo/espaço", foram transcritas as respostas que pontuam dificuldades em relação à atenção, à organização pessoal e aos horários. Abaixo, encontra-se a cópia de algumas delas:

Manter a atenção (E15).

Organização dos horários (E7).

De tirar dúvidas, são muito mais difíceis de acabar entendendo. Outra é a distração de estar em casa, sempre acaba tendo algo distraindo. Mas vamos firme que logo passa (E22).

Acho que não se distrair com as coisas que temos ao redor, principalmente por estar em casa, onde sempre há alguma coisa para fazer/olhar (E32).

Foco durante a aula e a falta de interação que o distanciamento causa (E18).

Os depoimentos dos pesquisados confirmam que as aulas virtualizadas dificultam a concentração pelo fato de ocorrerem fora do ambiente escolar. Ademais, estudantes e professores, muitas vezes, não possuem espaços estruturados e equipados para a realização das tarefas escolares, que, não raro, são compartilhados com outras pessoas da família, envolvendo, inclusive, as atividades domésticas, como apontado por E32: "sempre há alguma coisa para fazer/olhar". Esses afazeres podem abranger desde a limpeza da casa até o cuidado com filhos e/ou adultos, o que acaba conflitando com o horário das aulas. Por sua vez, nas presenciais, esse conflito é atenuado pelo espaço da sala de aula. Nesse contexto, Lima (2020, p. 73) pontua que

O ambiente universitário, não apenas a sala de aula, mas os espaços de convivência, como as bibliotecas e as salas de estudos, pode ser o refúgio para muitos alunos que buscam concentração para realização de atividades acadêmicas. Casas cheias, barulhos e distrações aparecem como fatores que dificultam a aprendizagem. Se em contexto de normalidade os alunos podem usar os espaços universitários para os estudos, principalmente nos contraturnos de seus cursos, nesse momento precisam utilizar os diversos cômodos da casa para isso. Nesse contexto, não só os ambientes físicos são compartilhados, mas os equipamentos também. Algumas vezes, um só 
computador deve servir a todos os familiares que se revezam para dar conta das demandas.

Em relação à questão "O que você considera produtivo nas aulas virtualizadas?", dentre as respostas, destacam-se, as que indicam pontos positivos, como o conforto de estar em casa, o que diminui o tempo de ir até a Universidade, bem como os gastos em relação a transportes, conforme consta no depoimento de A7: "A questão de não ter a perda de tempo com transporte, torna meu horário mais flexível, sobra mais tempo para estudar". Esse pensamento é corroborado por E16 ao declarar que "Acho que as aulas virtualizadas poupam uma boa quantidade de tempo devido ao deslocamento até a universidade não ser necessário e também dinheiro".

Outro ponto salientado foi a disponibilidade de diversos recursos nas aulas virtualizadas, com destaque à possibilidade de gravação das aulas, consoante à resposta de E9: "Gosto muito da opção de ter aulas gravadas, esta opção ajuda muito na hora de revisar algum conteúdo". Na mesma linha, E28 comenta que "As gravações que são feitas, principalmente em aulas como de Cálculo, são fundamentais, pois pequenos detalhes que você deixa escapar, você consegue recuperar olhando a gravação." Por sua vez, E13 destaca a possibilidade de fazer prints: "As imagens que são colhidas através de prints da tela, às vezes não dá tempo de copiar para o caderno e um print da tela se torna muito prático".

Salienta-se que as aulas virtualizadas na Instituição são ministradas pelo google meet, plataforma que possibilita ao professor desenvolver aulas de maneira interativa, dialogar com os estudantes, além de sanar possíveis dúvidas no decorrer da discussão. Ademais, existe a disponibilidade de gravar todos os momentos da aula, e os links das gravações ficam disponíveis aos estudantes, que podem assistir ao(s) vídeo(s) quando sentirem necessidade. Essa prática já se tornou um hábito no decorrer das aulas virtualizadas, pois cabe a um dos alunos iniciar a gravação caso o professor esqueça de realizá-la. No começo do semestre, é acordado que os vídeos são para estudos e não podem ser disponibilizados em redes sociais.

Outro ponto positivo destacado pelos estudantes foi a exploração de exercícios no decorrer das aulas virtualizadas de Cálculo I:

Exemplos práticos e exercícios corrigidos juntos, isso ajuda muito nas dificuldades (E22).

Acredito que pela aula estar virtualizada, fica mais fácil surgirem dúvidas durante a realização de atividades, do que na explicação. Então, considero produtiva a realização de muitas atividades, para assim surgirem mais dúvidas (E31).

Acredito ser muito produtivo explicar e em seguida já passar exercícios para prática (E33).

Sendo assim, pode-se inferir que os estudantes entendiam o conteúdo quando realizavam os exercícios, pois as dúvidas que poderiam surgir seriam sanadas. Portanto, em aulas virtualizadas, é importante o professor disponibilizar um tempo para a realização de tarefas. Entretanto, sabe-se que esses momentos concedidos aos alunos para realizálas diferem dos das aulas presenciais, pois o fato de poucos deles abrirem suas câmeras impede que a turma seja observada como na modalidade presencial. Musiau et al. (2020, p. 18) salientam que, neste novo cenário, as "dinâmicas tradicionais do ambiente escolar mudaram radicalmente, pois se antes bastava o estudante erguer o braço para tirar dúvidas depois de uma explicação, agora são mediadas por telas, com o uso de ferramentas e aplicativos". Na mesma linha argumentativa, Costa (2020, p. 5) comenta que "Esse aspecto merece uma relevância, tendo em vista que se tem observado, nos depoimentos dos 
professores, a tendência dos estudantes de permanecerem com a câmera desativada durante todas as aulas, o que reduz as possibilidades de mediação e interação." Nesse contexto, cabe ao docente utilizar outros meios para que a interação seja produtiva.

A disponibilidade do professor para auxiliar os estudantes também foi considerada importante e contribui positivamente para a compreensão dos conteúdos:

Professores estão à disposição dos alunos tanto quanto nas aulas presenciais (E27).

Considero produtivo quando a professora consegue fazer uma boa explicação do conteúdo (E2).

A agilidade e o conforto, porém tendo o apoio e ajuda da (o) professora (o) isso facilita muito, pois mesmo sendo em um ambiente virtual, ele acaba sendo bem diferente do que é um EAD, onde tem-se apenas as matérias para estudar (E15).

As enunciações acima transcritas evidenciam a importância da explicação detalhada do professor para o entendimento do estudante, que também ocorre no presencial. A resposta de E19 reforça as explicações docentes e acrescenta as plataformas utilizadas: "Vejo que apesar de não ser como as aulas presenciais a Instituição está utilizando ótimas plataformas e ótimos métodos de explicações (claro que depende do professor), mas tem também o lado bom que é receber explicações num lugar bem cômodo (em casa)." De fato, os professores da Instituição tiveram diversas oficinas sobre o uso de ferramentas que podem ser utilizadas nas aulas virtualizadas. Esses momentos de formação proporcionados pela Universidade foram essenciais para a qualidade das aulas virtualizadas.

No que tange à questão "Que sugestões você daria para as nossas aulas virtualizadas de Cálculo I?", as respostas foram organizadas em cinco grupos, a saber: sem sugestão (oito estudantes); uso de exercícios e atividades (quinze); uso do quadro (quatro); exemplos detalhados (quatro); aulas gravadas (três).

Nota-se que a maioria dos estudantes cita o uso de exercícios e atividades no decorrer das aulas. As respostas comprovam a afirmação:

Bastante tarefas para que os alunos possam praticar bastante em casa, assim como trabalhos em equipe, para que os alunos possam debater entre si o que é proposto em aula (E8).

Mais atividades para serem efetuadas em sala de aula (E13).

Sempre manter bom número de exercícios extras, com gabarito para conferência, e nas aulas o esclarecimento de dúvidas pontuais. Acredito ser o principal ainda mais em disciplinas de cálculo, onde a repetição de exercícios é muito importante (E30).

A minha sugestão é que tenhamos uma parte da aula que seja focada em realizar exercícios sobre o assunto, pois na minha opinião não existe método melhor de aprendizado do que a prática. Mas é claro sem deixar a parte teórica de lado, pois é a teoria a base da prática (E32).

Tempo para resolver questões, pois assim acabam surgindo bastante dúvidas, e por estar em tempo de aula, tem a professora e a monitora disponíveis para tirar as dúvidas na hora (E12).

Atividades em grupos, para que tenha interação da turma (E27).

Em suas respostas, os estudantes atestam que tinham necessidade de fazer exercícios para aprender os conteúdos, sejam individuais ou em grupos. Também salientam ser primordial a concessão de tempo, durante as aulas, para o desenvolvimento das tarefas e sanar dúvidas. Aliado a isso, destacam a importância de o professor utilizar o quadro no decorrer das explicações do conteúdo: 
Uso de quadro para a resolução das questões e para tirar as dúvidas. (Porém isso só funciona se tiver uma qualidade de internet para ter uma imagem visível, pois se a internet estiver fraca, os pixels da imagem ficam maiores para redução de resolução da tela fazendo com que rode sem travar da melhor maneira possível, então, para isso, deve-se ter uma boa internet) (E6).

Uma sugestão é o uso de um quadro, pode até ser digital que facilita um pouco (E19).

Se possível o uso de quadro para demonstrar como fazer as questões ou outra forma digitalizada com passo a passo (E20).

As declarações acima evidenciam que o quadro era/é considerado um recurso significativo para o entendimento do conteúdo por acompanhar, gradualmente, a resolução de questões. Dessa forma, os alunos vão revisando alguns conceitos importantes para o conteúdo que está sendo estudado. Nesse contexto, a professora de Cálculo I comprou um quadro branco e o usou sistematicamente em suas aulas. Destaca-se que, mesmo utilizando textos explicativos, resoluções de questões, slides no decorrer das aulas, os estudantes, constantemente, solicitavam que ela usasse o quadro para resolução das questões.

No que consiste à questão aplicada no final do semestre, em que os estudantes deveriam "Escrever de quatro a dez linhas, destacando dificuldades e aprendizagens ocorridas no decorrer desse semestre, na disciplina de Cálculo I", as citações foram diversificadas. Em razão do espaço limitado, escolheram-se as que retratam a opinião da maioria da turma.

Em sua escrita, E10 demonstra a preocupação de as aulas de Cálculo I serem de forma virtualizada:

Em Cálculo I, no início tinha como expectativa que iria ser uma cadeira bem difícil, ainda mais sendo virtualizada. Sempre tive dificuldades em Cálculo. Assim, imaginava que a cadeira, por ser virtualizada, me traria maiores dificuldades, mas aconteceu ao contrário. Felizmente consegui aprender os diversos cálculos ensinados pela professora. Junto com aulas gravadas e com explicações tanto em slides e no quadro, ficou mais fácil o aprendizado, assim tendo um ótimo resultado em aprendizado e notas ao final do semestre. Foi muito bom ter as aulas gravadas, onde eu mesmo conseguia rever aqueles conceitos os quais eu tinha dificuldade (E10).

A narrativa de E10 representa outras que destacam a importância das aulas gravadas, do uso de slides e do quadro para o entendimento dos conteúdos desenvolvidos no decorrer do semestre. E15 enfatiza a necessidade da concentração para uma aprendizagem mais efetiva.

Este semestre foi marcado por um grande acontecimento. Algo que nos obrigou a sair das aulas presenciais. Eu diria que minha maior dificuldade neste semestre e no anterior foi a atenção, ou no caso, a falta dela. Mas atenção no sentido de foco. Qualquer coisa já me distraía e eu perdia uma parte da aula. Coisa que no presencial não aconteceria. Tirando esse fato, eu creio que por tudo ser novo ainda para mim, estou iniciando agora este ano o curso, e esse momento de adaptação foi um pouco complicado. Mas, é só uma questão de me acostumar com a rotina.

Constata-se, assim, que a adaptação para o novo contexto de aulas virtualizadas não é algo tão trivial. Musiau et al. (2020, p. 21) destacam que os estudantes, por estarem habituados ao ensino presencial, "tiveram que passar por adaptações e enfrentar 
dificuldades, que abrangem não somente a disponibilidade de equipamentos e rede de dados, mas ainda aspectos como organização pessoal e disciplina, para que se dedicassem às aulas online assim como quando estavam diante do docente." Portanto, o Ensino Remoto Emergencial mudou a rotina de estudo, da organização pessoal do estudante e também do professor. Assim, como E15, E12 comenta que,

Assim que começaram as aulas virtuais, tive muita dificuldade para me adequar. Para mim, aulas de matemática precisam ser presenciais. É muito ruim para tirar dúvidas no formato virtual, além de não conseguir prestar atenção. O lado bom é que a gente tem muito mais recurso para aprender estando em casa.

Nesse contexto, desafiador e diferenciado para o estudante, a figura do professor é importante, pois a cultura do presencial é muito forte na escola. A mudança foi muito rápida. $\mathrm{E}$, mesmo que no virtualizado, docentes e estudantes estejam conectados em tempo real, as dificuldades persistem. Neste sentido, é importante que o professor promova momentos de feedback construtivo no decorrer das aulas, pois, de acordo com Moreira, Henriques e Arruda (2020, p. 361), "o estudante necessita dele para compreender o seu desempenho. Os autores salientam que há necessidade de cuidar que o espaço online de aula não deve ser apenas "um repositório de conteúdos digitais", mas sim um momento ativo, interativo e dinâmico entre os alunos, bem como um espaço de informações sobre as atividades que estão sendo desenvolvidas.

O relato do estudante E24 enfatiza os conteúdos aprendidos no decorrer do semestre, salientando, novamente, os momentos de exercícios nas aulas virtualizadas:

A parte de integrais, achei mais complexo e com uma exigência maior do que as derivadas. Olhei também alguns vídeos de exemplos, fiz os exercícios das listas e consultei alguns livros para aprender. Gostei da didática que foi usada nas aulas de fazer os exercícios no quadro, pois assim a gente acompanhava passo a passo. De modo geral, gostei bastante da disciplina. Creio que para os próximos cálculos devo estudar mais, mas creio que estou preparado para os próximos desafios da graduação (E24).

A importância dos exercícios e o uso do quadro para entender o conteúdo também foram mencionados por E30:

As dificuldades foram mais no começo do semestre onde as dúvidas eram maiores e ainda não usávamos quadro para a explicação, mas no decorrer do semestre e com o auxílio do quadro ficou mais fácil de entender, uma coisa que ajudou também foi a resolução dos exercícios nos slides, pois algumas vezes a internet não estava muito boa e a qualidade do quadro ficava um pouco ruim de enxergar. Mas no final deu tudo certo, e espero que para o próximo semestre já melhore esta pandemia e as aulas retornem aos poucos.

Portanto, apesar de algumas dificuldades em relação às aulas virtualizadas, tais como acesso à internet, problemas de concentração, conteúdo considerado complexo, os estudantes declararam que a aprendizagem aconteceu. No que concerne aos conteúdos da disciplina, o entendimento, segundo os pesquisados, ocorreu em razão das explicações detalhadas, exercícios realizados, uso do quadro, bem como a exposição dos vídeos. Nesse sentido, Costa (2020) sublinha que a mudança brusca imposta por um fator externo, a epidemia do Covid-19, possibilitou que "a comunidade pudesse dar uma nova chance à Educação mediada por tecnologias, sem preconceitos e sabendo separar o joio do trigo." 


\section{CONCLUSÃO}

O intuito deste texto foi analisar dificuldades, potencialidades e sugestões, destacadas pelos estudantes em relação ao Ensino Remoto Emergencial (ERE), na disciplina de Cálculo I. Quanto às primeiras, elas estão relacionadas aos conteúdos de matemática, em particular à falta de base. Os alunos também citaram a organização tempo/espaço, pois como estão em casa, esse ambiente não oferece a tranquilidade e infraestrutura adequadas para o estudo e, consequentemente, tiram o foco e a atenção dos alunos no decorrer das aulas. Antes da investigação, tinha-se a ideia de que problemas de conexão com a internet seria uma das maiores dificuldades dos estudantes; entretanto, ela foi citada por apenas quatro (uma minoria).

No que diz respeito às potencialidades, os estudantes apontaram o uso das gravações do google meet, do quadro, dos vídeos disponíveis na internet, a resolução detalhada de exercícios e exemplos dados pelo professor. Além disso, como eles permanecem em casa, economizam tempo e dinheiro, o que não ocorria quando se deslocavam até a Universidade.

As potencialidades destacadas pelos estudantes, bem como as sugestões, tais como uso do quadro, exercícios, vídeos, explicações detalhadas, foram incluídas na metodologia da professora, o que produziu reflexos na resposta da questão aplicada na prova final. Por meio dos dados desta, os pesquisados declararam que entenderam os conteúdos desenvolvidos no decorrer da disciplina. Portanto, pode-se inferir que, nas aulas virtualizadas, eles compreenderam os da disciplina de Cálculo I. Mas, para isso, houve a necessidade do envolvimento ativo da professora e da turma. Entende-se que o docente precisa usar meios diversos para que aconteça a interação dos alunos no decorrer da aula, explicar detalhadamente o conteúdo, bem como conceder tempo para eles realizarem as atividades. Por sua vez, os discentes precisam manter o foco, atenção, concentração durante as aulas virtualizadas, além de participarem ativamente das atividades propostas pelo professor.

Destaca-se, outrossim, que, apesar dos pontos positivos em relação ao ensino virtualizado, os estudantes expressaram o desejo de voltarem às aulas presenciais, pois sentem falta do ambiente acadêmico da Instituição, de estarem com os colegas e professores e conversarem no intervalo das aulas. Mas, diante do contexto atual da Pandemia do Covid-19, tudo acaba sendo incerto e ficam alguns questionamentos: Como será o retorno das aulas para o modelo presencial? As tecnologias digitais continuarão incluídas como algo do ser e fazer da prática pedagógica do professor? Os alunos passarão a pedir o uso de mais recursos tecnológicos? São interrogações para pensar.

\section{REFERÊNCIAS}

\section{BEHAR, P. A. O Ensino Remoto Emergencial e a Educação a Distância -}

Coronavírus. 6 Jul. 2020. Disponível em: https://www.ufrgs.br/coronavirus/base/artigo-oensino-remoto-emergencial-e-a-educacao-a-distancia/. Acesso em: 24 Abr. 2021.

BEZERRA, I. M. P. Estado da arte sobre o ensino de enfermagem e os desafios do uso de tecnologias remotas em época de pandemia do Coronavírus.

Journal of Human Growth and Development, 30(1):141-147, 2020.

BIOTTO, C. N.; SERRA, S. M. B. EXPERIÊNCIA DE ENSINO REMOTO EMERGENCIAL NA PÓS-GRADUAÇÃO EM ENGENHARIA. In: XLVIII CONGRESSO BRASILEIRO DE 
EDUCAÇÃO EM ENGENHARIA, 2020. Anais do XLVIII Congresso Brasileiro de Educação em Engenharia (COBENGE) [...]. [S. I.]: Associação Brasileira de Educação em Engenharia, 2020. https://doi.org/10.37702/COBENGE.2020.3232.

COSTA, L. A. C. Desafios e avanços educacionais em tempos da COVID-19: a docência no Ensino Remoto em cursos de Engenharia. Revista de Estudos e Pesquisas sobre Ensino Tecnológico (EDUCITEC), vol. 6, p. e152920, 18 Dez. 2020. https://doi.org/10.31417/educitec.v6.1529.

DEMO, P. Educar pela pesquisa. 9a ed. Campinas, SP: Autores Associados, 2011.

DUTRA; SILVA, A., et al. INTERDISCIPLINARIDADE E ENSINO REMOTO: OS DESAFIOS DA APRENDIZAGEM EM ENGENHARIA NO DISTANCIAMENTO SOCIAL. Anais do Seminário de Atualização de Práticas Docentes, 2 Out. 2020. Disponível em: http://anais.unievangelica.edu.br/index.php/praticasdocentes/article/view/5715. Acesso em: 02 maio 2021.

FERREIRA, L.; ABREU ROBALLO, E.; DENARDIN DA SILVEIRA, B.; MUNARI VOGEL, $H$. ANÁLISE DA RECEPTIVIDADE DAS ATIVIDADES DE ENSINO REMOTO EMERGENCIAIS PELOS DISCENTES DA ENGENHARIA FLORESTAL. Anais do Salão Internacional de Ensino, Pesquisa e Extensão, v. 12, n. 1, 20 Nov. 2020.

\section{JUSTINO, G. Após percalços, educação pode ter legado positivo com superação} durante a pandemia. 15 Mai 2020. Disponível em:

https://gauchazh.clicrbs.com.br/educacao-e-emprego/noticia/2020/05/apos-percalcoseducacao-pode-ter-legado-positivo-com-superacao-durante-a-pandemiacka8v2r0o002g015n6h3yarv5.html. Acesso em: 23 Abr. 2021.

LIMA, F. B. de. Ensino remoto em tempos de Covid-19: percepções de alunos do curso de Letras. Palimpsesto - Revista do Programa de Pós-Graduação em Letras da UERJ, vol. 19, no. 34, p. 60-78, 18 Dez. 2020. https://doi.org/10.12957/palimpsesto.2020.54136.

MENDES, B. P.; SANTOS, B. S.; BRUNO HENRIQUE MENDES FERREIRA; SANTOS, B. F. Vantagens e Desvantagens do Ensino Remoto Emergencial no Brasil. Anais do Congresso Nacional Universidade, EAD e Software Livre, 30 Mar. 2021. Disponível em: http://www.periodicos.letras.ufmg.br/index.php/ueadsl/article/view/18149. Acesso em: 02 maio 2021.

MOREIRA, J. A. M.; HENRIQUES, S.; BARROS, D. Transitando de um ensino remoto emergencial para uma educação digital em rede, em tempos de pandemia. Dialogia, no. 34, p. 351-364, 3 Jun. 2020. https://doi.org/10.5585/dialogia.n34.17123.

MUSIAU, P. M.; ALVES, G. P.; VANUCHI, V. C.; GABRIEL, F. A.; SILVA, W. L. ENSINO DE CÁLCULO DIFERENCIAL E INTEGRAL NO CONTEXTO DA COVID-19: UM RELATO DE EXPERIÊNCIA NO ENSINO SUPERIOR. Revista Saberes UNIJIPA, vol. 18, no. Edição especial, p. 14-23, 2020. Disponível em: https://unijipa.edu.br/wpcontent/uploads/sites/2/2020/11/02-ENSINO-DE-C\%C3\%81LCULO-DIFERENCIAL-EINTEGRAL-NO-CONTEXTO-DA-COVID-19-UM-RELATO-DE-EXPERI\%C3\%8ANCIANO-ENSINO-SUPERIOR-VOL.-18.pdf. Acesso em: 4 Mai 2021. 
SAMPIERI, R. H.; COLLADO, C. F.; LUCIO, M. del P. B. Metodologia de Pesquisa. [S. I.]: Penso, 2013. vol. 5.

SANTOS, E. H. L.; DONATO, L. M.; OTONI, T. P.; WEIDE, H.; WERNER, E. ANÁLISE DE RECURSOS DIDÁTICOS E METODOLOGIAS UTILIZADOS POR PROFESSORES EM TEMPOS DE ENSINO REMOTO EMERGENCIAL. In: CONGRESSO INTERNACIONAL DE EDUCAÇÃO E TECNOLOGIAS | ENCONTRO DE PESQUISADORES EM EDUCAÇÃO A DISTÂNCIA, 24 Ago. 2020. [S. I.]: São Carlos, 24 Ago. 2020. Disponível em: https://cietenped.ufscar.br/submissao/index.php/2020/article/view/1231/907. Acesso em: 24 Abr. 2021.

\title{
THE POTENTIALITY AND DIFFICULTIES OF ENGINEERING STUDENTS IN CALCULUS I DURING THE PANDEMICS
}

\begin{abstract}
This article describes an inquiry conducted with 34 students enrolled in Calculus I during the second semester of 2020. The aim of this study was to look into the challenges, opportunities, and suggestions made by students regarding Emergency Remote Education (ERE) in the discipline of Calculus I. Initially, to obtain this information, a questionnaire containing open-ended questions about virtualized classes in the topic of Calculus I was made available for the students. At the end of the semester, they answered a broader question with related aspects. The responses of both instruments were investigated and tied together with theoretical references. As a result, students cite time/space mismanagement and a lack of a mathematical basis as factors hindering their ability to comprehend such issue. The no need of in-person classes, the use of the board, detailed exercises, and recordings of the explanations via Google Meet are all potential benefits acknowledged by the students. At the end of the semester, participants highlighted that they assimilated Calculus I topics; however, in order to be effective, the teacher needed to use a variety of methods, especially those that stimulate students to actively participate in classes. Finally, the student must maintain attention and concentration and must participate in the activities proposed.
\end{abstract}

Keywords: Virtualized classes. Calculus I. Difficulties and potentialities. 